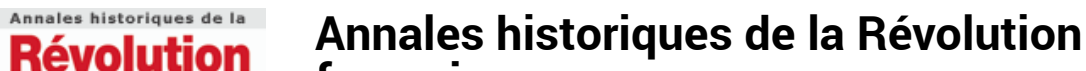 \\ française française
}

339 | janvier-mars 2005

Varia

\section{Yves Bénot (1920-2005)}

\section{Marcel Dorigny}

\section{OpenEdition}

\section{Journals}

Édition électronique

URL : https://journals.openedition.org/ahrf/2232

DOI : 10.4000/ahrf.2232

ISSN : 1952-403X

Éditeur :

Armand Colin, Société des études robespierristes

Édition imprimée

Date de publication : 1 mars 2005

Pagination : 151-154

ISSN : 0003-4436

\section{Référence électronique}

Marcel Dorigny, «Yves Bénot (1920-2005)». Annales historiques de la Révolution française [En ligne], 339 | janvier-mars 2005, mis en ligne le 27 avril 2006, consulté le 23 avril 2022. URL : http:// journals.openedition.org/ahrf/2232 ; DOI : https://doi.org/10.4000/ahrf.2232

Ce document a été généré automatiquement le 23 avril 2022.

Tous droits réservés 


\title{
Yves Bénot (1920-2005)
}

\author{
Marcel Dorigny
}

1 Né le 23 décembre 1920 de parents juifs roumains réfugiés en France dès avant la Première Guerre mondiale, Édouard Helman est décédé le 3 janvier 2005. Connu sous son nom de plume d'Yves Bénot (pseudonyme dont il ne donna jamais de commentaires sur l'origine et la signification), il se construisit assurément une vie et une carrière en dehors des chemins battus.

2 Ayant un père et une sœur - son aînée de dix ans - médecins, il n'a pas suivi cette voie familiale, mais s'est doté d'une solide formation littéraire classique, doublée d'une maîtrise des langues anglaise et italienne. Son père, qui exerçait la médecine à La Fertésous-Jouarre, en Seine-et-Marne, fut déporté avec son épouse le 29 octobre 1943, au camp d'extermination d'Auschwitz où ils furent exécutés à leur arrivée ${ }^{1}$. Alors âgé de presque vingt-trois ans, Yves Bénot passa en Angleterre pour rejoindre la France libre, en compagnie d'Armand Gatti.

3 Après la Libération, tout en se liant aux milieux littéraires proches des surréalistes, il entama une carrière d'enseignant et de journaliste, d'abord au Maroc, en 1951 et 1952, où il était professeur de français et collaborateur au journal de la CGT marocaine (Le Petit Marocain, puis Les Nouvelles marocaines). De retour à Paris, il collabora au second quotidien du Parti communiste dirigé par Aragon, Ce Soir ; puis aux Lettres françaises (de 1953 à 1956), dont Aragon assurait également la direction après la suppression de $\mathrm{Ce}$ Soir. En 1947, il avait été l'un des deux organisateurs de la célèbre séance du Vieux Colombier où Antonin Artaud fit son retour public après sa longue période d'internement à Rodez; Breton, Gide, Gatti étaient présents à ce spectacle qui fit scandale dans la presse bien-pensante. Yves Bénot a témoigné, notamment dans la revue Europe en 1984, sur la genèse de cette séance et de sa rencontre avec Artaud.

Mais l'essor du mouvement de la fin des années 1950 vers les indépendances africaines le conduisit en Afrique noire, dont il devint rapidement un des spécialistes : en Guinée ex-française d'abord, pays où il fut enseignant au lycée de Conakry de 1959 à 1962, et surtout au Ghana où il fut directeur adjoint du Ghana Institute of Languages de 1962 à 1964. De cette expérience africaine, Yves Bénot conserva des liens étroits avec bon nombre d'intellectuels, aujourd'hui universitaires ou hommes politiques de premier 
plan en Afrique de l'Ouest, tel Paulin Houtondji, ministre de la Culture du Bénin lors de la «transition démocratique » du milieu des années 1990, ou Boubacar Barry, historien à l'Université Cheik Anta Diop de Dakar. Ce contact approfondi avec l'Afrique des indépendances fut également à l'origine de deux de ses ouvrages importants, Idéologies des indépendances africaines (Maspéro, 1969, rééd. 1972) et Indépendances africaines. Idéologies et réalités (Maspéro, 2 vol., 1975), ainsi que de nombreux articles publiés dès le début des années 1960 dans Europe, La Pensée, Présence africaine ou Démocratie nouvelle.

5 À partir de cet ensemble de travaux sur les sociétés africaines et sur les processus d'accession à l'indépendance, Yves Bénot soutint sa thèse de doctorat d'État en 1976 devant l'Université de Paris-8, sous le titre Fonctions historiques des idéologies et de la science d'après l'exemple de l'Afrique noire. N'ayant aucunement l'intention de se lancer dans une carrière universitaire, il ne fit que très rarement mention de son titre de docteur ès lettres, ignoré de la plupart de ses amis et proches collaborateurs. De 1965 à 1986, « faute de mieux » comme il tenait à le dire, il a été enseignant de lettres dans un lycée de la région parisienne. Mais sa vraie vie était ailleurs.

6 Sa trajectoire scientifique et intellectuelle a en effet été marquée, dès les années 1950, par son intérêt pour l'histoire de la colonisation et surtout pour les fondements idéologiques de l'esclavage et de la conquête coloniale. Ce fut ainsi qu'il rencontra deux penseurs $d u x_{\text {XIII }}{ }^{e}$ siècle de tout premier plan, dont il contribua de façon décisive à donner une connaissance renouvelée de leurs engagements dans les débats de leur temps sur la traite négrière, l'esclavage et la colonisation européenne: Guillaume Thomas Raynal et Diderot. Il a commencé par publier quelques textes inconnus ou peu connus de Diderot: Mystification (Éditeurs français réunis, 1954), Le Pour et le Contre (Éditeurs français réunis, 1954), Textes politiques (Éditions sociales, 1960).

7 Son Diderot, de l'athéisme à l'anticolonialisme (Maspero, 1970 ; rééd. La Découverte, 1981), devenu un classique, repose sur l'utilisation de la correspondance de Diderot conservée à la BNF dans le fonds Vandeul. Il publia également une édition abrégée et commentée de la fameuse Histoire philosophique et politique des deux Indes (Maspero, 1981), de l'abbé Raynal - à laquelle Diderot apporta une contribution décisive, alors méconnue. Enfin, depuis le milieu des années 1980, l'attention d'Yves Bénot se porta de plus en plus sur la période révolutionnaire aux colonies, sans le conduire à renoncer à des sujets plus contemporains, comme Les députés africains au Palais-Bourbon (Chaka, 1989) ou Massacres coloniaux. 1944-1950 : la IVe République et la mise au pas des colonies françaises (La Découverte, 1994 ; rééd. en poche, 2001).

8 Mais désormais, le centre de gravité de ses recherches s'était déplacé vers la fin du $\mathrm{XVIII}^{\mathrm{e}}$ siècle et surtout la Révolution. Trois ouvrages majeurs, publiés presque à la suite, contribuèrent de façon décisive à faire entrer l'histoire des révolutions coloniales à l'intérieur même de la Révolution française et de son prolongement napoléonien : La Révolution et la fin des colonies (La Découverte, 1987 ; rééd. en 1988 puis en 2004 en format de poche), La démence coloniale sous Napoléon (La Découverte, 1992), La Guyane sous la Révolution ou l'impasse de la Révolution pacifique (Ibis rouge Éditions, 1997). Une voie féconde était ouverte pour l'histoire des liens indissociables entre Lumières, Révolution française et processus d'abolition de l'esclavage.

9 À ces trois ouvrages phares, Yves Bénot ajouta un grand nombre de communications données aux nombreux colloques internationaux suscités par le calendrier des commémorations en France, en Italie, aux Antilles françaises, en Afrique noire et au Maghreb, en Haïti, aux États-Unis récemment encore : 1989, 1993, 1994, 1998 et, en 
2002, le sinistre anniversaire du rétablissement de l'esclavage par Bonaparte ; et encore en 2004, à l'occasion du bicentenaire de l'indépendance d'Haïti, cette "Première République noire" qui lui tenait tant à cœur. Dans la même période, il a donné de nombreux articles à des revues savantes et notamment aux Annales historiques de la Révolution française, où il publia articles et documents inédits à partir de 1991 et jusqu'au présent numéro ; il fut l'un des collaborateurs les plus assidus de Dix-huitième siècle, autant par ses articles érudits (le numéro 36, paru en décembre 2004, contient ce qui sera l'un de ses derniers articles) que par ses nombreuses notes de lecture et son travail de correcteur vigilant des épreuves ; il collabora également à Europe, aux Cahiers des Anneaux de la Mémoire et à bien d'autres revues encore qu'il est impossible de toutes citer ici.

10 Yves Bénot fut ainsi de tous les combats intellectuels pour faire connaître ce volet de l'histoire coloniale trop souvent refoulé hors de la mémoire collective. Il fut aussi à l'initiative de la fondation, en 1991, d'un groupe de recherche sur les liens entre Révolution française et colonies au sein de l'I.H.R.F. alors à son apogée sous la direction de M. Vovelle. Ce groupe informel se transforma, en octobre 1993, en Association pour l'étude de la colonisation européenne 1750-1850, dont il assura la présidence jusqu'à sa mort. Cette société savante se donnait pour objectif de réintégrer l'histoire de l'esclavage et des abolitions dans l'histoire générale du «siècle des révolutions». Les colloques internationaux organisés par cette association, en grande partie sous l'autorité d'Yves Bénot, contribuèrent largement à stimuler les recherches, nationales et internationales, et à en faire connaître à un large public les acquis. La large diffusion et la traduction anglaise de ces actes de colloques (notamment celui sur Les Abolitions de l'esclavage, 1793-1794-1848, Éditions Unesco et Presses Universitaires de Vincennes, 1995 ; rééd. en 1998, traduction anglaise en 2003 ; et celui sur 1802, rétablissement de l'esclavage dans les colonies françaises. Aux origines d'Haïti, Maisonneuve et Larose, 2003), mais également du recueil d'études sur Grégoire et la cause des Noirs. 1789-1831, ou des actes du colloque de 1991 consacré à Léger-Félicité Sonthonax, la première abolition de l'esclavage, la Révolution française et la Révolution de Saint-Domingue (Société Française d'Histoire d'outremer/APECE, 1997, rééd en 2005) témoignent de l'ampleur de ce renouveau des études sur des sujets tabous il y a peu d'années encore. La contribution d'Yves Bénot à ce renouveau fut décisive et est magistralement déployée dans son dernier livre, qui restera comme la synthèse de son œuvre, paru à la fin de 2003, La modernité de l'esclavage. Essai sur l'esclavage au cœur du capitalisme (La Découverte).

11 La place progressivement occupée dans ses travaux par la Révolution française et la question coloniale le conduisit tout naturellement à adhérer à la Société des études robespierristes, en mars 2000.

12 Esprit farouchement indépendant, parfois vigoureusement polémique, Yves Bénot n'a certes pas fait ce qu'il est convenu d'appeler une "carrière » universitaire - il s'est même soigneusement tenu à l'écart de ce qu'il considérait comme le «conformisme académique ». Mais il a réalisé une œuvre, au plein sens du terme, ce qui est beaucoup plus important. Et cette œuvre a profondément marqué la recherche et a fait école. 


\section{NOTES}

1.Cette fin tragique à Auschwitz est mentionnée à la fois par le « fichier Klarsfeld » des victimes de la Shoah et par l'inscription qui figure au Mémorial des martyrs juifs inauguré à Paris au début de 2005 ; cependant une conviction acquise par des membres de la famille donne une version différente, selon laquelle le docteur Jean Helman et son épouse auraient été fusillés à Metz au cours du voyage entre le camp de Drancy et le camp d'extermination d'Auschwitz. Faute de trace des événements de Metz de la fin octobre 1943 dans les archives, du moins connues aujourd'hui, nous ne pouvons trancher entre ces deux versions tout autant tragiques.

\section{AUTEUR}

\section{MARCEL DORIGNY}

Université de Paris-8,

Vice-président de l'Association pour l'étude de la colonisation européenne 1750-1850. 